\title{
Increasing autonomy through improved care: effects of a professional care-giver training programme on the functional status of older adults
}

\author{
Elena Navarro $^{1}$ (D), Miriam Sanjuán ${ }^{1 \star}$ (D) and M. Dolores Calero ${ }^{2}$ (D) \\ ${ }^{1}$ Department of Personality, Assessment and Psychological Treatment, Faculty of Psychology, University of \\ Granada, Granada, Spain and ${ }^{2}$ Research Center on Mind, Brain and Behavior (CIMCYC), University of \\ Granada, Granada, Spain \\ ${ }^{\star}$ Corresponding author. Email: mirsanjuan@ugr.es
}

(Accepted 25 March 2021; first published online 7 May 2021)

\begin{abstract}
The aim of the present research was to evaluate the effectiveness of a care-giver training programme that trains professional care-givers in cognitive stimulation strategies for functional maintenance in care-dependent older adults. The sample contained 69 older adults (37 in the treatment group, 32 control group) assessed with the Barthel Index, the Mini-Mental State Examination and the Clifton Assessment Procedure for the Elderly (Cognitive Scale). Participants in the treatment group were treated by professional care-givers who were trained with the programme CUIDA-2 in communication and cognitive stimulation strategies. The results from the Barthel Index showed significant differences in the post-intervention assessment and in the follow-up assessment, where the treatment group obtained higher scores, and there were significant differences within the treatment group between the initial assessment and the post-treatment assessment, as well as between the initial assessment and the follow-up. The data obtained reflect that a training programme to train professional care-givers produced functional benefits in the older adults, and these improvements persisted over time. Moreover, the care-givers saw themselves as more competent and more satisfied with their work.
\end{abstract}

Keywords: functional skill; professional care-givers; cognitive stimulation; care-giver training; cognitive capacity

\section{Introduction}

Ageing of the world's population is becoming one of the most significant social transformations of the 21st century (United Nations, 2017). These transformations will involve great changes in family structures, in society, economics, the job market and the demand for services. According to a United Nations report, the proportion 
of older adults will double by 2050 and triple by 2100 . Europe shows the same trend as the worldwide population: older adults, making up 28.8 per cent of the population in 2015, will increase to 49 per cent in 2050, and the 80-89-year-old population in particular rises from 5.5 per cent in 2015 to 12.7 per cent in 2050 (Eurostat, 2018).

These data foretell problems in the years to come in relation to health-care needs, pensions and social protections for this population group. Consequently, measures must be found for maintaining quality of life in this ageing group, as well as for preventing functional decline and situations of dependency (García, 2014; Manfredi et al., 2019). Support, independence and self-management in older adults must be maintained for as long as possible.

When observing the ageing population, we find that their main concerns are loss of autonomy and independence in their day-to-day life (Liu et al., 2018). Functional disability is defined as loss of the ability to carry out activities of daily living (ADLs) independently (Pérès et al., 2005; Albert et al., 2011), and can be assessed by measuring the person's ability to carry out such activities (Calero-García and Lendínez, 2015).

According to the scientific literature, functional performance of older adults is closely related to their cognitive status (Cano-Gutiérrez et al., 2017). The loss of cognitive abilities has been shown to have an important impact on the ability of older adults to carry out ADLs (Rozo et al., 2016; Huang et al., 2019). Thus, neuropsychological impairment, above all in executive functions and memory, is correlated with functional limitations in ADLs (Farias et al., 2013) both in normally ageing persons (Farias et al., 2009), and in persons with mild cognitive impairment (Jefferson et al., 2008) or dementia (Razani et al., 2007). This leads to greater dependence and reduced quality of life (Mograbi et al., 2014).

An especially significant finding in this area is that of a critical window for intervention: the time period when an older adult presents mild functional limitations but is still independent in their ADLs. During this period of time, the application of cognitive training can hold back advancement of the disability (Willis et al., 2006; Rebok et al., 2014) confirming the idea that training in cognitive functions at this time can improve an older adult's functional capacity in their day-to-day life (Greenaway et al., 2013; Jacoby et al., 2013).

Several reviews on the effect of cognitive interventions in older adults have been published in the past decade (Mewborn et al., 2017; Bahar-Fuchs et al., 2019; Simon et al., 2020). Cognitive stimulation programmes are shown to be effective, producing gains in the cognitive performance of older adults (Smart et al., 2017; Bhome et al., 2018; Lobbia et al., 2018; Gavelin et al., 2020), with positive effects maintained over periods of two months to five years (Kelly et al., 2014; Chiu et al., 2017). The concern is whether the effects of such training programmes become transferred to overall cognitive functioning, and if they produce functional gains in the daily life of the older adults, since this ought to be the final objective of all these programmes. Some studies have found the transfer of cognitive training benefits to certain functional domains (Hampstead et al., 2013). Nevertheless, transfer and generalisation to daily life have proven to be complicated and minimal (Borella et al., 2010; Richmond et al., 2011) and findings indicate that transfer to daily life is quite difficult (Tardif and Simard, 2011; Von Bastian et al., 2013). 
Today there are data to suggest that adapted training programmes, where levels of difficulty and types of tasks are fitted to the individual, seem to yield better results in terms of transfer (Cândea et al., 2015; Calero, 2019).

For all these reasons, it seems of interest to involve the professional caregivers of older adults as active agents who would incorporate cognitive training into the daily life of these persons. This might be a way to improve the transfer of training results and meet the goal of more autonomous older adults who are more independent in their day-to-day life. From this perspective, professional care-givers are considered facilitators of cognitive training transfer, helping to generalise its effects, since they would be able to help maintain it over time.

Certain care-giver training programmes already exist, but most are oriented to improving the quality of life of the care-givers themselves - to lighten their load, improve their frame of mind, offer them self-help resources, lower their stress, etc. (Harrad and Sulla, 2018; Cheng et al., 2019) - but not to how they can help the older adults manage their own health or be autonomous, even though caregivers often ask for this type of training (Hartmann et al., 2018). In recent years an increasing number of programmes have been designed to train professional caregivers in care-giving skills. In this line, we find programmes that train professional care-givers in care strategies, communication, knowledge of disease and intervention guidelines for eliminating behaviour problems (Goyder et al., 2012; Spector et al., 2016; Robertson et al., 2017; Bravo-Benítez and Navarro-González, 2018; Sanjuán et al., 2018).

The STAR programme, for example, was designed to train professional caregivers to address problems of interaction with older adults and to reduce affective and behavioural anxiety (Teri et al., 2005). Other programmes (Broughton et al., 2011; Bird et al., 2016; Mills et al., 2017) seek to implement strategies for improved communication, such as the MESSAGE programme (facilitating communication in dementia) and RECAPS (improving memory and cognition in dementia). Both of these have shown positive effects in memory and communication, in the caregiver's knowledge and ease, and in increased quality of life in the older adults (Broughton et al., 2011; Robertson et al., 2017). A recently published programme, called CUIDA-2 (Calero et al., 2017), trains care-givers in communication strategies and cognitive, physical and emotional stimulation. The programme is based on the model of person-focused care and uses mediation-based methodology, with guidelines for care-givers on how to train older adults as part of their day-to-day caregiving (Calero et al., 2017).

The general objective of the present research was to evaluate the effectiveness of the cognitive stimulation part of the CUIDA-2 programme in improving the functional status of older adults. The specific objectives were (a) to verify any improvement of functional skill in older adults under the care of professional care-givers who had received the training, compared to a control group whose care-givers did not receive this training, and (b) to analyse whether-in addition to functional improvement-there was cognitive improvement in older people under the care of professional care-givers who had received training, compared to a control group whose care-givers did not receive the training. 


\section{Method}

\section{Participants}

\section{Older adults}

The participants in this study were 69 care-dependent older adults (37 in the treatment group and 32 in the control group). The mean age of the persons selected was 84.12 years (standard deviation $(\mathrm{SD})=7.47$ ). Men represented 14.5 per cent of the sample and women represented 85.5 per cent. Regarding the level of education, 21.7 per cent were unschooled, 62.3 per cent had elementary schooling, 10.1 per cent had secondary or vocational training, and 5.8 per cent had higher education or university training. Thirteen per cent were married, 10.1 per cent were single, 4.3 per cent were divorced and 72.5 per cent were widowed. The older adults were selected from three day care centres (59.4\%) and four residences (40.6\%) in the province of Granada, southern Spain. Characteristics of the two groups of older adults are shown in Table 1. As can be observed, there were no significant between-group differences.

The inclusion criteria for the older adults were: age 55 or older, receiving care, living at a senior residence or attending a senior day care centre for a minimum of 40 hours per week, not suffering from dementia, having given their informed consent and having initial Barthel Index scores of less than 75 points. Using these criteria, we sought to select older adults who presented mild functional limitations but were still independent in their ADLs. This population sector, according to the literature reviewed in the Introduction, are the ones who can benefit most from a cognitive intervention for improving their functional ability (Greenaway et al., 2013; Jacoby et al., 2013; Rebok et al., 2014).

The treatment group $(\mathrm{N}=37)$ received care from professional care-givers who were trained in communication strategies, cognitive and functional stimulation, and increased autonomy, through the CUIDA-2 programme (Calero et al., 2017) (see description in the Intervention Programme section). The control group $(\mathrm{N}=32)$ was composed of older adults selected from the same centres and matched in age and gender to the treatment group, such that there were no significant differences in any socio-demographic variable between participants in the two groups.

\section{Professional care-givers}

There were 44 participating care-givers ( 22 for the treatment group and 22 for the control group). The mean age for all care-givers was 37.36 years $(S D=10.73)$. Male care-givers represented 18.2 per cent of the sample and female care-givers represented 81.8 per cent. Regarding the level of education, 4.5 per cent had elementary schooling only, 65.9 per cent had secondary or vocational training, and 29.5 per cent had higher education or university training. At the work locations where this investigation was carried out, the average number of adults under the care of each professional care-giver was $34.5(\mathrm{SD}=23.63)$. For the purposes of this research, however, this load was reduced to 12 older adults per care-giver. In the case of the treatment group, although each care-giver was assigned 12 older adults to care for on a daily basis, they applied the programme with only one or two of the people assigned to them. Specifically, 15 care-givers applied the programme with two older adults each, and seven care-givers applied the programme with one 
Table 1. Characteristics of the older adults

\begin{tabular}{|c|c|c|c|}
\hline & Treatment group & Control group & Statistical test \\
\hline $\mathrm{N}$ & 37 & 32 & \\
\hline \multicolumn{4}{|l|}{ Age: } \\
\hline Mean & 83.84 & 84.44 & \multirow{2}{*}{$\begin{aligned} F_{69} & =0.109 \\
p & =0.742 \\
\text { eta } & =0.002 \\
O P & =0.062\end{aligned}$} \\
\hline SD & 7.37 & 7.68 & \\
\hline \multicolumn{4}{|c|}{ Percentages } \\
\hline \multicolumn{4}{|l|}{ Sex: } \\
\hline Male & 13.5 & 15.6 & \multirow{2}{*}{$\begin{aligned} \chi^{2} & =0.062 \\
p & =0.804 \\
\text { eta } & =0.030\end{aligned}$} \\
\hline Female & 86.5 & 84.4 & \\
\hline \multicolumn{4}{|l|}{ Marital status: } \\
\hline Married & 8.1 & 18.8 & \multirow{4}{*}{$\begin{array}{r}\chi^{2}=4.279 \\
p=0.233 \\
\text { eta }=0.226\end{array}$} \\
\hline Single & 5.4 & 15.6 & \\
\hline Divorced & 5.4 & 3.1 & \\
\hline Widowed & 81.1 & 62.5 & \\
\hline \multicolumn{4}{|l|}{ Education: } \\
\hline No education & 24.3 & 18.8 & \multirow{4}{*}{$\begin{array}{r}\chi^{2}=1.598 \\
p=0.660 \\
\text { eta }=0.117\end{array}$} \\
\hline Elementary & 62.2 & 62.5 & \\
\hline Secondary & 10.8 & 9.4 & \\
\hline Higher education & 2.7 & 9.4 & \\
\hline \multicolumn{4}{|l|}{ Place of recruitment: } \\
\hline Day care centre & 59.5 & 59.4 & \multirow{2}{*}{$\begin{aligned} \chi^{2} & =0.000 \\
p & =0.994 \\
\text { eta } & =0.000\end{aligned}$} \\
\hline Senior residence & 40.5 & 40.6 & \\
\hline
\end{tabular}

Notes: SD: standard deviation. eta: effect size. OP: observed power.

person. The care-givers in the control group were also assigned 12 older adults to care for on a daily basis. From this set of older adults, a group of 32 persons homogeneous with the treatment group was randomly selected.

The mean number of years they had been working in the care of older adults was 9.64 years $(S D=6.16)$. Finally, professional care-givers were selected from the same centres as the older adults; these were the care-givers responsible for providing care to the older adult participants. All of them were professional care-givers, that is, they were employees at the centres where this research was carried out. Regarding workplace distribution, 68.2 per cent worked at senior residences and 31.8 per cent in adult day care centres.

There were no significant differences in any of the above variables between caregivers in the treatment group and care-givers in the control group, as shown in Table 2, which presents characteristics of the two groups. 
Table 2. Characteristics of the professional care-givers

\begin{tabular}{|c|c|c|c|}
\hline & Treatment group & Control group & Statistical test \\
\hline $\mathrm{N}$ & 22 & 22 & \\
\hline \multicolumn{4}{|l|}{ Age: } \\
\hline Mean & 34.91 & 39.82 & \multirow{2}{*}{$\begin{aligned} F_{43} & =2.377 \\
p & =0.131 \\
\text { eta } & =0.054 \\
\text { OP } & =0.325\end{aligned}$} \\
\hline SD & 10.13 & 10.98 & \\
\hline \multicolumn{4}{|l|}{ Years of experience: } \\
\hline Mean & 8.91 & 10.36 & \multirow{2}{*}{$\begin{aligned} F_{43} & =0.608 \\
p & =0.440 \\
\text { eta } & =0.014 \\
\text { OP } & =0.119\end{aligned}$} \\
\hline SD & 6.42 & 5.94 & \\
\hline \multicolumn{4}{|c|}{ Total residents under their care: } \\
\hline Mean & 28.14 & 40.86 & \multirow{2}{*}{$\begin{aligned} F_{43} & =3.366 \\
p & =0.074 \\
\text { eta } & =0.074 \\
\text { OP } & =0.434\end{aligned}$} \\
\hline SD & 12.09 & 30.21 & \\
\hline \multicolumn{4}{|c|}{ Percentages } \\
\hline \multicolumn{4}{|l|}{ Sex: } \\
\hline Male & 22.7 & 13.6 & \multirow{2}{*}{$\begin{aligned} \chi^{2} & =0.611 \\
p & =0.434 \\
\text { eta } & =0.118\end{aligned}$} \\
\hline Female & 77.3 & 86.4 & \\
\hline \multicolumn{4}{|l|}{ Marital status: } \\
\hline Married & 27.3 & 50 & \multirow{4}{*}{$\begin{array}{r}\chi^{2}=4.971 \\
p=0.174 \\
\text { eta }=0.143\end{array}$} \\
\hline Single & 54.5 & 27.3 & \\
\hline Divorced & 13.6 & 22.7 & \\
\hline Widowed & 4.5 & - & \\
\hline \multicolumn{4}{|l|}{ Education: } \\
\hline Elementary & - & 9.1 & \multirow{3}{*}{$\begin{array}{r}\chi^{2}=2.111 \\
p=0.348 \\
\text { eta }=0.129\end{array}$} \\
\hline Secondary & 68.2 & 63.6 & \\
\hline Higher education & 31.8 & 27.3 & \\
\hline \multicolumn{4}{|l|}{ Place of recruitment: } \\
\hline Day care centre & 68.2 & 68.2 & \multirow{2}{*}{$\begin{aligned} \chi^{2} & =0.000 \\
p & =1.000 \\
\text { eta } & =0.000\end{aligned}$} \\
\hline Senior residence & 31.8 & 31.8 & \\
\hline \multicolumn{4}{|c|}{ Professional qualification: } \\
\hline Aide & 77.3 & 81.8 & \multirow{2}{*}{$\begin{aligned} \chi^{2} & =0.140 \\
p & =0.709 \\
\text { eta } & =0.056\end{aligned}$} \\
\hline Licenciado $^{1}$ & 22.7 & 18.2 & \\
\hline
\end{tabular}

Notes: $\mathrm{SD}=$ standard deviation. eta = effect size. OP: observed power. 1 . Having a university degree. 
The inclusion criteria for the professional care-givers were: (a) to be the caregiver of older adults who had been selected for this study, and therefore, an employee of the centres where the older adults were recruited, and (b) give informed consent to participate, involving a commitment to take the training course and apply it to the persons under their care in the residential facility or day care centre where they worked.

\section{Assessment instruments}

The following instruments were used for the older adults:

- Socio-demographic data sheet: here we recorded participant data pertaining to personal variables, medical and social information, and their preferences and hobbies.

- The Barthel Index (Granger et al., 1979 version, adapted to Spanish by Cid-Ruzafa and Damián-Moreno, 1997) was used to measure the level of dependency. This scale assesses the person's functional ability based on ten items that analyse their ability to carry out basic activities like getting up from a chair or a bed, personal hygiene, bathroom use, going outside, going up and down stairs, dressing and sphincter control. Scores can range from 1 (completely dependent) to 100 (fully independent). Internal consistency presents an alpha coefficient between 0.86 and 0.92 and inter-judge reliability is between 0.84 and 0.97 . This test has proven to be a good predictor of mortality and can detect gains or decline in aspects of the individual's functional skills. Optimal structural validity and internal consistency have been demonstrated in a population similar to our study population (Bernaola-Sagardui, 2018).

- The following instruments were used for the cognitive part:

(1) Mini-Mental State Examination (MMSE; Folstein et al., 1975). For this research we used the Spanish adaptation (Mini-Examen-Cognoscitivo (MEC); Lobo et al., 1979). The MEC is sensitive to detecting cognitive status in an older Spanish population with a low level of education (Manubens et al., 1998). The final score is normally used as a global index in processes such as cognitive impairment and dementia. We used standards developed for the Spanish population (Manubens et al., 1998) to establish criteria for the presence or absence of cognitive impairment. The validity of these standards was confirmed in a previous study (Calero et al., 2000).

(2) The Procedimiento de Evaluación Clifton para Ancianos - Escala cognitive (CAPE) (Fernández-Ballesteros and Guerrero, 1984), a Spanish adaptation of the Clifton Assessment Procedure for the Elderly-Cognitive Scale (Pattie and Gilleard, 1979). This instrument contains two scales, one cognitive and one behavioural. The present study made use of the cognitive assessment scale. Its test-retest reliability falls between 0.79 and 0.90 , and between 0.61 and 0.69 for the information and orientation scale and for the mental skill scale, respectively. It also has convergent validity with Wechsler's Memory Scale, showing a 0.90 correlation between the two. 
For the care-giver assessment, we used a data sheet to collect information on all the care-givers' socio-demographic and work-related variables. Care-givers for the treatment group were also assessed using the Star Staff Feedback Questionnaire (SSFQ) (Goyder et al., 2012) which assesses the degree to which the training was useful and satisfactory for the care-givers.

\section{Intervention programme}

The care-giver training programme consisted of applying the cognitive stimulation module of the CUIDA-2 programme (Calero et al., 2017). This application included theoretical training in three modules that covered: (a) person-focused care, (b) communication strategies, and (c) mediated cognitive training strategies. The first module explains the working approach of the Person-Centered Care Model (Brownie and Nancarrow, 2013), encouraging care-givers to follow these principles in their work, so that the older adult under their care would improve in autonomy and decision-making ability. The second module explains the communication strategies needed for communicating with older adults, in order to facilitate the interchange and the relationship. The final module explains and works on mediated cognitive training strategies (Tzuriel, 2013) for the different cognitive functions that decline in older adults. This model is more extensive and seeks to equip professional care-givers with the tools they need to stimulate older adults on a daily basis and thus ensure better cognitive maintenance. This module develops cognitive trainers that follow a mediated approach for analysis, training and generalisation of basic cognitive skills. This train-the-trainer module was administered to the treatment care-giver group in two two-hour group sessions, followed by 50 hours of hands-on training that consisted of individual, on-the-job practice, supervised by psychologists who were experts in the programme. During these 50 hours, the care-givers implemented the programme by integrating it into their regular interaction with the older adults under their care. Supervision was conducted by direct observation and by weekly meetings to answer questions and help the professional care-givers fill in their log of activities carried out with each older adult. In these weekly logs, care-givers had to plan in advance what activities they were going to carry out with the older adult, and once completed, record how they were carried out and how the older adult responded.

\section{Procedure}

First, permission was obtained from the Research Ethics Committee at the University of Granada. The residential facilities and day care centres which had agreed to participate in the research were then contacted and the final sample was formed as described above.

Once we had obtained informed consent from the facilities, the care-givers and the older adults, the following phases where implemented. We started with the initial assessment of care-givers and older adults from the control and treatment groups, and afterwards administered the training programme in small-group format to the care-givers in the treatment group. Once the training course was finalised, the care-givers of the treatment group put into practice what they had 
learned, working with the older adults for three months under the supervision of the research team. This supervision consisted of direct observation during the first week, weekly meetings to answer questions and helping care-givers with their running log of activities. The log was a weekly register where the care-giver had to first plan the activities they were going to carry out with the older adult, and afterwards record how they were done and how the older adult had responded. The care-givers of the control group, however, did not participate in any training nor were they supervised in their daily work. After the programme application, we administered a post-treatment assessment of all the care-givers and older adults. Finally, a follow-up was carried out and both groups were re-assessed six months after the post-treatment assessment.

\section{Design}

We used a quasi-experimental design with repeated measures (pre, post and follow-up) of the different dependent variables. The statistical analyses were analyses of variance, following the univariate and multivariate analysis of the general linear model (GLM) for inter-group comparisons, and repeated-measures analysis through the general linear model in order to check for intra-group differences at three assessment times, as well as the effect size of the study variables. Data analyses were performed using SPSS 19.0 for Windows.

\section{Results}

In order to check whether the care-giver training programme produced functional improvement in members of the treatment group, inter-group and intra-group differences in the Barthel Index were analysed using an GLM $3 \times 2$ analysis (Time $\times$ Group).

As seen in Table 3 and Figure 1, no significant inter-group differences in the Barthel Index were observed in the pre-assessment $\left(F_{67}=0.774 ; p=0.382\right.$; $d=0.011$ ), but there were significant inter-group differences in the post-treatment assessment $\left(F_{67}=4.901 ; p=0.030 ; d=0.068\right)$ and in the follow-up $\left(F_{67}=10.503\right.$; $p=0.002 ; d=0.136$ ), when the control group obtained lower scores than the treatment group (Table 3 and Figure 1).

Regarding intra-group differences in the Barthel Index (see Table 3), significant differences were found between the initial assessment and the post-treatment assessment $\left(F_{67}=7.037 ; p=0.010 ; d=0.095\right)$, between the post-treatment and the follow-up $\left(F_{67}=7.905 ; p=0.000 ; d=0.174\right)$ and between the initial assessment and the follow-up $\left(F_{67}=14.108 ; p=0.023 ; d=0.075\right)$, with treatment group scores increasing significantly over time, while control group scores declined from one assessment to the next.

To check whether the care-giver training programme brought about cognitive improvement in the treatment group, inter-group and intra-group differences in the Barthel Index were analysed for the three assessments (see Table 4), based on changes in the MMSE and CAPE using an MLG $3 \times 2$ analysis (Time $\times$ Group).

As for the MMSE, no significant inter-group differences were observed at any assessment time, neither in the pre-assessment $\left(F_{67}=0.093 ; p=0.762 ; d=0.001\right)$ 
Table 3. Means and $F$ scores obtained by the older adults in the control and treatment groups in the Barthel Index, in the pre-treatment (Pre), post-treatment (Post) and follow-up (Follow) assessments

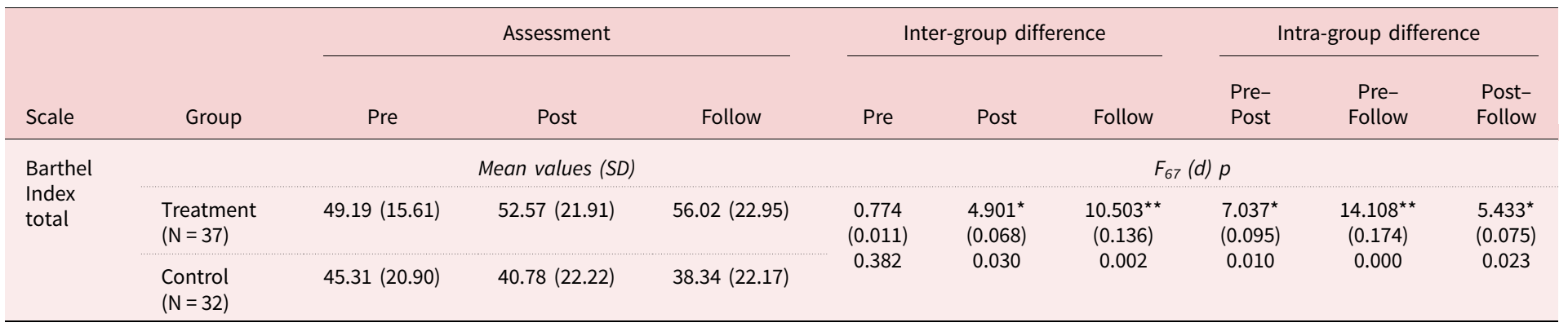

Notes: SD: standard deviation. d: effect size.

Significance levels: ${ }^{*} p<0.05,{ }^{\star \star} p<0.01$. 


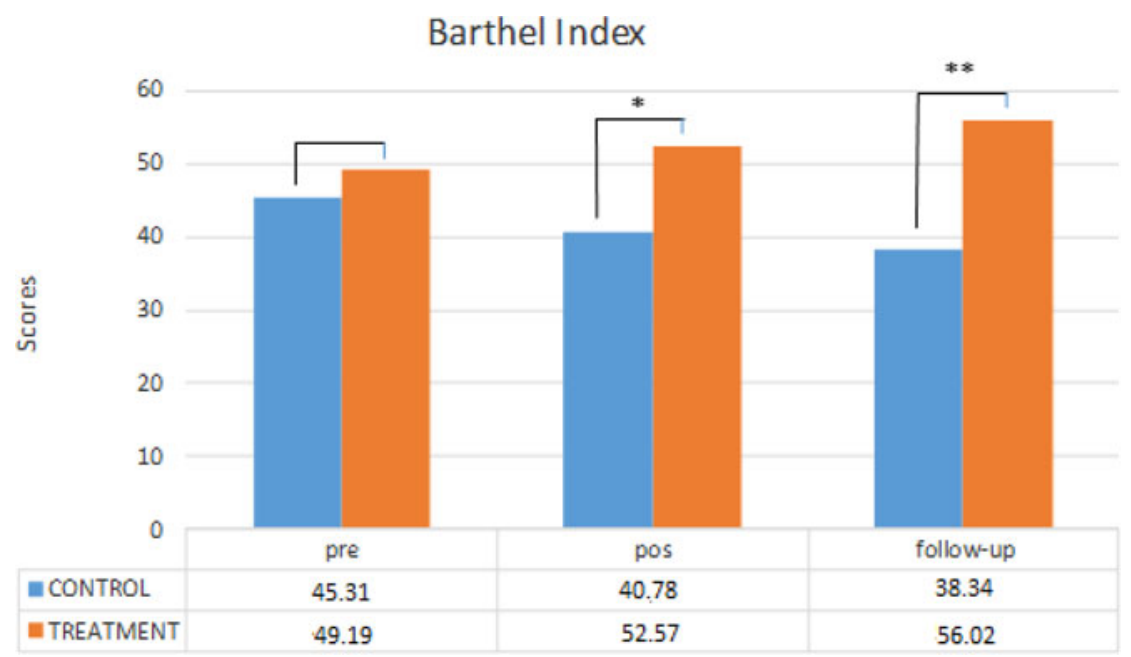

Figure 1. Significant difference between the treatment group and the control group on the Barthel Index at three different assessment times.

Notes: pre: pre-treatment. pos: post-treatment.

Significance levels: ${ }^{\star} p<0.05,{ }^{\star \star} p<0.01$.

nor in the post-assessment $\left(F_{67}=0.606 ; p=0.439 ; d=0.009\right)$ nor in the follow-up $\left(F_{67}=0.229 ; p=0.634 ; d=0.003\right)$ (see Table 3$)$. Neither were there any significant intra-group differences between the initial assessment and the post-treatment assessment $\left(F_{67}=0.569 ; p=0.453 ; d=0.008\right)$, between the post-assessment and the follow-up $\left(F_{67}=0.191 ; p=0.663 ; d=0.003\right)$ or between the initial assessment and the follow-up assessment $\left(F_{67}=0.095 ; p=0.759 ; d=0.001\right)$ (Table 4$)$.

Regarding the CAPE test, as can be seen in Table 4, no significant inter-group differences were obtained at any assessment time, neither in the pre-assessment $\left(F_{67}=1.600 ; p=0.210 ; d=0.023\right)$ nor in the post-treatment assessment $\left(F_{67}=\right.$ $3.274 ; p=0.075 ; d=0.047)$ nor in the follow-up $\left(F_{67}=2.133 ; p=0.149 ; d=\right.$ $0.031)$. Neither were there any significant intra-group differences between the initial assessment and the post-treatment assessment $\left(F_{67}=0.483 ; p=0.490 ; d=0.007\right)$, between the post-assessment and the follow-up $\left(F_{67}=0.018 ; p=0.893 ; d=0.000\right)$ or between the initial assessment and the follow-up assessment $\left(F_{67}=0.264 ; p=\right.$ $0.609 ; d=0.004$ ) (Table 4).

Nonetheless, even though the results were not statistically significant, one could observe that MMSE scores in the treatment group remained stable throughout the pre-, post- and follow-up assessments, and the CAPE scores remained stable from pre- to post-assessment; while these scores declined in the control group (see Table 4).

We conducted a qualitative analysis of how care-givers from the treatment group rated the training received. Their responses to the SSFQ showed that they positively rated the usefulness of the programme modules, producing a mean of $4.9(\mathrm{SD}=$ 0.301 ) on a scale from 0 to 5 . The care-givers also indicated that participation in the programme had been a very positive experience and had helped increase 


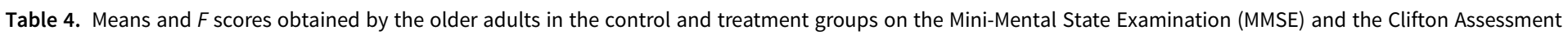
Procedure for the Elderly - Cognitive Scale (CAPE), in the pre-treatment (Pre), post-treatment (Post) and follow-up (Follow) assessments

\begin{tabular}{|c|c|c|c|c|c|c|c|c|c|c|}
\hline \multirow[b]{2}{*}{ Scale } & \multirow[b]{2}{*}{ Group } & \multicolumn{3}{|c|}{ Assessment } & \multicolumn{3}{|c|}{ Inter-group difference } & \multicolumn{3}{|c|}{ Intra-group difference } \\
\hline & & Pre & Post & Follow & Pre & Post & Follow & Pre-Post & Pre-Follow & Post-Follow \\
\hline & & \multicolumn{3}{|c|}{ Mean values (SD) } & \multicolumn{6}{|c|}{$F_{67}(d) p$} \\
\hline \multirow[t]{2}{*}{ MMSE total } & Treatment $(\mathrm{N}=37)$ & $\begin{array}{l}26.49 \\
(5.13)\end{array}$ & $\begin{array}{l}26.95 \\
(5.93)\end{array}$ & $\begin{array}{l}26.55 \\
(5.87)\end{array}$ & \multirow{2}{*}{$\begin{array}{c}0.093 \\
(0.001) \\
0.762\end{array}$} & \multirow{2}{*}{$\begin{array}{c}0.606 \\
(0.009) \\
0.439\end{array}$} & \multirow{2}{*}{$\begin{array}{c}0.229 \\
(0.003) \\
0.634\end{array}$} & \multirow{2}{*}{$\begin{array}{c}0.569 \\
(0.008) \\
0.453\end{array}$} & \multirow{2}{*}{$\begin{array}{c}0.095 \\
(0.001) \\
0.759\end{array}$} & \multirow[t]{2}{*}{$\begin{array}{c}0.191(0.003) \\
0.663\end{array}$} \\
\hline & Control $(\mathrm{N}=32)$ & $\begin{array}{l}26.13 \\
(4.65)\end{array}$ & $\begin{array}{l}25.94 \\
(4.62)\end{array}$ & $\begin{array}{l}25.94 \\
(4.64)\end{array}$ & & & & & & \\
\hline \multirow[t]{2}{*}{ CAPE total } & Treatment $(\mathrm{N}=37)$ & $\begin{array}{l}27.24 \\
(4.63)\end{array}$ & $\begin{array}{l}27.22 \\
(5.65)\end{array}$ & $\begin{array}{l}25.99 \\
(6.33)\end{array}$ & \multirow{2}{*}{$\begin{array}{c}1.600 \\
(0.023) \\
0.210\end{array}$} & \multirow{2}{*}{$\begin{array}{c}3.274 \\
(0.047) \\
0.075\end{array}$} & \multirow{2}{*}{$\begin{array}{c}2.133 \\
(0.031) \\
0.149\end{array}$} & \multirow{2}{*}{$\begin{array}{c}0.483 \\
(0.007) \\
0.490\end{array}$} & \multirow{2}{*}{$\begin{array}{c}0.264 \\
(0.004) \\
0.609\end{array}$} & \multirow[t]{2}{*}{$\begin{array}{c}0.018(0.000) \\
0.893\end{array}$} \\
\hline & Control $(\mathrm{N}=32)$ & $\begin{array}{l}25.66 \\
(5.79)\end{array}$ & $\begin{array}{l}24.84 \\
(5.16)\end{array}$ & $\begin{array}{l}23.82 \\
(5.99)\end{array}$ & & & & & & \\
\hline
\end{tabular}

Notes: SD: standard deviation. $d$ : effect size. 
their knowledge, satisfaction and sense of confidence on the job. For these reasons, they expressed their willingness to participate again in this type of programme. They also indicated that the main drawback encountered in implementing the programme was the short amount of time they have for attending to each adult.

\section{Discussion}

The general objective of this study was to evaluate whether functional improvement was produced in older adults who receive care from professionals that participated in a care-giver training programme.

Information provided by the Barthel Index was our basis for establishing the functional skill of the older adults, thereby verifying whether this skill was improved/maintained in the older adults who received care from the trained caregivers. The Barthel Index thus represented mastery of the skills being targeted by the care-givers. The intervention programme was designed to be implemented in the course of daily activity, such that functional skill would be worked on constantly through cognitive exercises. The Barthel Index was then expected to detect differences produced by the training.

The present study confirms that the older adults whose professional care-givers participated in the cognitive training programme significantly improved in functional skill with respect to the older adults whose care-givers did not receive this training. The ability of cognitive training to improve ADL functional ability in older adults is thus verified (Mograbi et al., 2014; Lau et al., 2015). The increase in score was produced on every scale of the Barthel Index. This finding agrees with previous literature showing that cognitive training can be generalised to functional skills (Greenaway et al., 2013; Cândea et al., 2015). For instance, regarding the association between executive functions and functional performance, previous studies found that executive functions could predict performance in instrumental ADLs (Bell-McGinty et al., 2002). Another research group (Cahn-Weiner et al., 2007) investigated episodic memory and executive functions in older adults and found severe executive dysfunction to be associated with a more rapid decline in ADLs. Similarly, a strong association was found between ADLs and performance on a verbal fluency task in a sample of persons with dementia (Maseda et al., 2014). All these studies confirm that cognitive functions are closely tied to a person's daily functioning.

In light of the significantly improved scores attained by older persons with initial Barthel Index scores equal to or less than 75 (meaning they were dependent), their functional skill has clearly benefited from the training. Moreover, these gains that represent progress towards greater independence in ADLs (Nirmalan, 2010) were maintained over six months. These results indicate fulfilment of our purpose of obtaining functional improvements through cognitive training. Transfer from the training to the older adult's daily life, and maintenance over time, have been demonstrated. The purpose of involving the professional care-givers was for them to make the connection between the cognitive task and day-to-day functioning. The care-givers were able to adapt the different cognitive tasks and adjust them to each older adult's environment and needs (Apóstolo et al., 2014; Williams et al., 2014). In our opinion, this individualised adaptation of the cognitive training 
(in the older adult's own setting and with objects and materials from their own daily life) was what helped produce this transfer of benefits from the cognitive training.

As for the cognitive tests, we found no significant differences between any of the assessments. We did observe, however, that cognitive scores in the treatment group remained stable from one assessment to the next, while scores in the control group were declining over the course of this study, even if the changes were not statistically significant. These results are in the line of studies indicating that cognitive interventions help to maintain and improve cognitive functioning in older adults (Bhome et al., 2018; Lobbia et al., 2018; Oltra-Cucarella et al., 2018).

The tests chosen to assess cognitive changes (MMSE and CAPE) contained tasks very distant from those that were trained; this may be responsible for the lack of significant changes at the cognitive level. Nonetheless, our results show that cognitive status was maintained in the older adults whose care-givers were trained in the programme.

Finally, we wished to ascertain whether the care-givers who received the training increased their knowledge and were satisfied with the programme received. All the care-givers rated the programme very positively, expressing general satisfaction with the programme, finding it useful, and that it increased their knowledge, their satisfaction with their work and their sense of confidence on the job. The following aspects of the training were indicated as most useful in their daily work: ascertaining the areas of greatest impairment in each adult, identifying exercises for these areas and learning how to perform them. Likewise, they reported having greater knowledge about the adults in their care, greater empathy towards them and greater ability to cope with them when they were worried or depressed. The main limitation noted, with regard to putting the programme into practice, was the short amount of time that they can dedicate to each of the older adults under their care. This problem suggests a need to increase care-giving resources and the number of professional care-givers assigned to work with older adults at these centres, hence, a lower ratio of older adults per care-giver. In this way, lack of time would no longer be a hindrance to proper care of the older adult.

Generally speaking, this training programme - which teaches care-givers how to communicate with the older adults, how to detect their deficits and to work on the deficient areas from an approach of person-centred care - produces transfer of cognitive benefits to the older adult's day-to-day functioning. Decrease in dependency is achieved, since the older adults' ADL functional ability has increased, and hence their autonomy and independence.

We were also able to verify that the effects were generalised, that is, maintained over time, given that the improvements continued to be found six months after the intervention.

Even so, this study presents certain limitations that should be taken into account in future research studies. One of these is the small sample size, which may be responsible for the lack of significance of some results. Another limitation would be the greater proportion of women in our sample, not allowing us to analyse possible gender-related differences. It would be interesting to analyse the differences in cognitive and functional benefits according to gender or other socio-demographic variables that may affect them. 
This study brings to light the importance of the figure of professional care-giver in maintaining the older adult's functional capacity. Data obtained here show that involving the professional care-giver in the training of an older adult is a novel aspect that contributes to generalisation and transfer of results.

Financial support. This work was supported by the Ministry of Education, Government of Spain (grant number FPU15/03966).

Ethical standards. Permission was obtained from the Research Ethics Committee at the University of Granada.

\section{References}

Albert MS, DeKosky ST, Dickson D, Dubois B, Feldman HH, Fox NC, Gamst A, Holtzman D, Jagust WJ, Petersen RC, Snyder PJ, Carrillo MC, Thies CH and Phelps CH (2011) The diagnosis of mild cognitive impairment due to Alzheimer's disease: recommendations from the National Institute on Aging-Alzheimer's Association workgroups on diagnostic guidelines for Alzheimer's disease. Alzheimer's and Dementia 7, 270-279.

Apóstolo JLA, Cardoso DFB, Rosa AI and Paúl C (2014) The effect of cognitive stimulation on nursing home elders: a randomized controlled trial. Journal of Nursing Scholarship 46, 157-166.

Bahar-Fuchs A, Martyr A, Goh AM, Sabates J and Clare L (2019) Cognitive training for people with mild to moderate dementia. Cochrane Database of Systematic Reviews 3, CD013069.

Bell-McGinty S, Podell K, Franzen M, Baird AD and Williams MJ (2002) Standard measures of executive function in predicting instrumental activities of daily living in older adults. International Journal of Geriatric Psychiatry 17, 828-834.

Bernaola-Sagardui I (2018) Validation of the Barthel Index in the Spanish population. Enfermería clínica 28, 210-211.

Bhome R, Berry AJ, Huntley JD and Howard RJ (2018) Interventions for subjective cognitive decline: systematic review and meta-analysis. BMJ Open 8, e021610.

Bird M, Anderson K, MacPherson S and Blair A (2016) Do interventions with staff in long-term residential facilities improve quality of care or quality of life for people with dementia? A systematic review of the evidence. International Psychogeriatrics 28, 1937-1963.

Borella E, Carretti B, Riboldi F and De Beni R (2010) Working memory training in older adults: evidence of transfer and maintenance effects. Psychology and Aging 25, 767-778.

Bravo-Benítez J and Navarro-González E (2018) Problemas de conducta en personas con demencia: eficacia de un programa de formación de cuidadores. Psicología Conductual 26, 159-175.

Broughton M, Smith ER, Baker R, Angwin AJ, Pachana NA, Copland DA, Humphreys MS, Gallois C, Byrne GJ and Chenery HJ (2011) Evaluation of a caregiver education program to support memory and communication in dementia: a controlled pretest-posttest study with nursing home staff. International Journal of Nursing Studies 48, 1436-1444.

Brownie S and Nancarrow S (2013) Effects of person-centered care on residents and staff in aged-care facilities: a systematic review. Clinical Interventions in Aging 8, 1-10.

Cahn-Weiner DA, Farias ST, Julian L, Harvey DJ, Kramer JH, Reed BR and Chui H (2007) Cognitive and neuroimaging predictors of instrumental activities of daily living. Journal of the International Neuropsychological Society 13, 747-757.

Calero-García MJ and Lendínez AJC (2015) Evolución del deterioro cognitivo y el nivel de dependencia en pacientes mayores de 65 años ingresados en un hospital de agudos: relación con las variables sociodemográficas. European Journal of Investigation in Health, Psychology and Education 4, 5-18.

Calero M (2019) Effects of environmental enrichment and training across life span in cognition. In Fernández-Ballesteros R, Benetos A and Robine J (eds), The Cambridge Handbook of Successful Aging. Cambridge: Cambridge University Press, pp. 321-354.

Calero MD, Navarro E, Robles $\mathbf{P}$ and García-Berbén T (2000) Validity study of Lobo's Mini-Examen-Cognitivo for the detection of cognitive impairment associated with dementia. Neurología 15, 337-342. 
Calero MD, Navarro E, Sanjuán M, Calero-García MJ and Ortega AR (2017) CUIDA-2. Madrid: Ediciones Pirámide.

Cândea DM, Cotet CD, Stefan S, Valenas SP and Szentagotai-Tatar A (2015) Computerized cognitive training for working memory in older adults: a review. Transylvanian Journal of Psychology 7, e40588.

Cano-Gutiérrez C, Bordaz MG, Reyes-Ortiz C, Arciniegas AJ and Samper-Ternent R (2017) Evaluación de factores asociados al estado funcional en ancianos de 60 años o más en Bogotá, Colombia. Biomédica 37, 57-65.

Cheng ST, Au A, Losada A, Thompson LW and Gallagher-Thompson D (2019) Psychological interventions for dementia caregivers: what we have achieved, what we have learned. Current Psychiatry Reports 21, 59.

Chiu HL, Chu H, Tsai JC, Liu D, Chen YR, Yang HL and Chou KR (2017) The effect of cognitive-based training for the healthy older people: a meta-analysis of randomized controlled trials. PLOS ONE 12, e0176742.

Cid-Ruzafa J and Damián-Moreno J (1997) Valoración de la discapacidad física: el índice de Barthel. Revista Española de Salud Pública 71, 127-137.

Eurostat (2018) Projected Old-age Dependency Ratio. Available at http://ec.europa.eu/eurostat/tgm/table. do? tab=tableandinit $=$ landlanguage $=$ enandpcode $=$ tps00200 andplugin $=1$.

Farias ST, Mungas D, Reed BR, Harvey D and DeCarli C (2009) Progression of mild cognitive impairment to dementia in clinic vs community-based cohorts. Archives of Neurology 66, 1151-1157.

Farias ST, Park LQ, Harvey DJ, Simon C, Reed BR, Carmichael O and Mungas D (2013) Everyday cognition in older adults: associations with neuropsychological performance and structural brain imaging. Journal of the International Neuropsychological Society 19, 430-441.

Fernández-Ballesteros R and Guerrero M (1984) Adaptación de Instrumentos de evaluación para ancianos. In I Congreso Nacional de Evaluación Psicológica.

Folstein MF, Folstein SE and McHugh PR (1975) 'Mini-mental state': a practical method for grading the cognitive state of patients for the clinician. Journal of Psychiatric Research 12, 189-198.

García R (2014) El envejecimiento activo: programa en competencia social con personas mayores (Unpublished master's thesis). Universidad de Valladollid, Valladollid, Spain.

Gavelin HM, Lampit A, Hallock H, Sabatés J and Bahar-Fuchs A (2020) Cognition-oriented treatments for older adults: a systematic overview of systematic reviews. Neuropsychology Review 30, 167-193.

Goyder J, Orrell M, Wenborn J and Spector A (2012) Staff training using STAR: a pilot study in UK care homes. International Psychogeriatrics 24, 911-920.

Granger CV, Dewis LS, Peters NC, Sherwood CC and Barrett JE (1979) Stroke rehabilitation: analysis of repeated Barthel index measures. Archives of Physical Medicine and Rehabilitation 60, 14-17.

Greenaway MC, Duncan NL and Smith GE (2013) The memory support system for mild cognitive impairment: randomized trial of a cognitive rehabilitation intervention. International Journal of Geriatric Psychiatry 28, 402-409.

Hampstead BM, Gillis MM and Stringer AY (2013) Cognitive rehabilitation of memory for mild cognitive impairment: a methodological review and model for future research. Journal of the International Neuropsychological Society 20, 135-151.

Harrad R and Sulla F (2018) Factors associated with and impact of burnout in nursing and residential home care workers for the elderly. Acta Biomedica 89, 60-69.

Hartmann CW, Mills WL, Pimentel CB, Palmer JA, Allen RS, Zhao S, Wewiorski NJ, Sullivan JL, Dillon K, Clark V, Berlowitz DR and Snow AL (2018) Impact of intervention to improve nursing home resident-staff interactions and engagement. The Gerontologist 58, e291-e301.

Huang F, Zhang M and Wang S (2019) Changes in cognitive function among older adults: a latent profile transition analysis. Archives of Gerontology and Geriatrics 80, 12-19.

Jacoby M, Averbuch S, Sacher Y, Katz N, Weiss PL and Kizony R (2013) Effectiveness of executive functions training within a virtual supermarket for adults with traumatic brain injury: a pilot study. IEEE Transactions on Neural Systems and Rehabilitation Engineering 21, 182-190.

Jefferson AL, Byerly LK, Vanderhill S, Lambe S, Wong S, Ozonoff A and Karlawish JH (2008) Characterization of activities of daily living in individuals with mild cognitive impairment. American Journal of Geriatric Psychiatry 16, 375-383. 
Kelly ME, Loughrey D, Lawlor BA, Robertson IH, Walsh C and Brennan S (2014) The impact of cognitive training and mental stimulation on cognitive and everyday functioning of healthy older adults: a systematic review and meta-analysis. Ageing Research Reviews 15, 28-43.

Lau KM, Parikh M, Harvey DJ, Huang CJ and Farias ST (2015) Early cognitively based functional limitations predict loss of independence in instrumental activities of daily living in older adults. Journal of the International Neuropsychological Society 21, 688-698.

Liu T, Luo H, Tang JY and Wong GH (2018) Does lifestyle matter? Individual lifestyle factors and their additive effects associated with cognitive function in older men and women. Aging and Mental Health 24, 405-412.

Lobbia A, Carbone E, Faggian S, Gardini S, Piras F, Spector A and Borella E (2018) The efficacy of cognitive stimulation therapy (CST) for people with mild-to-moderate dementia: a review. European Psychologist 24, 257-277.

Lobo A, Ezquerra J, Gómez F, Sala JM and Seva A (1979) El mini-examen cognoscitivo. Un test sencillo y práctico para detectar alteraciones intelectuales en pacientes médicos. Actas Luso-Españolas de Neurología, Psiquiatría y Ciencias Afines 7, 189-201.

Manfredi G, Midão L, Paúl C, Cena C, Duarte M and Costa E (2019) Prevalence of frailty status among the European elderly population: findings from the Survey of Health, Aging and Retirement in Europe. Geriatrics \& Gerontology International 19, 723-729.

Manubens JM, Martínez-Lage P, Martínez-Lage JM, Larrumbe R, Murazabal J and Martínez MA (1998) Variations in the Mini-Mental-State scores with age and level of education. Normative data for Pamplona's population older than 70 years old. Neurología 13, 111-119.

Maseda A, Lodeiro-Fernández L, Lorenzo-López L, Núñez-Naveira L, Balo A and Millán-Calenti JC (2014) Verbal fluency, naming and verbal comprehension: three aspects of language as predictors of cognitive impairment. Aging and Mental Health 18, 1037-1045.

Mewborn CM, Lindbergh CA and Miller LS (2017) Cognitive interventions for cognitively healthy, mildly impaired, and mixed samples of older adults: a systematic review and meta-analysis of randomizedcontrolled trials. Neuropsychology Review 27, 403-439.

Mills WL, Pimentel CB and Palmer JA Snow AL Wewiorski NJ Allen RS and Hartmann CW (2017) Applying a theory-driven framework to guide quality improvement efforts in nursing homes: The LOCK model. The Gerontologist 58, 598-605.

Mograbi DC, de Assis Faria C, Fichman HC, Paradela EMP and Lourenço RA (2014) Relationship between activities of daily living and cognitive ability in a sample of older adults with heterogeneous educational level. Annals of the Indian Academy of Neurology 17, 71-76.

Nirmalan V (2010) Modified Barthel Index and Self-assessment Scores of Level of Independence of Individuals in Subacute Care (Order No. 1484732). Available from ProQuest Dissertations \& Theses Global. (305239584). Retrieved from https://search.proquest.com/docview/305239584?accountid=14542.

Oltra-Cucarella J, Ferrer-Cascales R, Clare L, Morris SB, Espert R, Tirapu J and Sánchez-SanSegundo M (2018) Differential effects of cognition-focused interventions for people with Alzheimer's disease: a meta-analysis. Neuropsychology 32, 664-679.

Pattie AH and Gilleard CJ (1979) CLIFTON: Procedimientos para evaluación de ancianos: Manual. Madrid: Tea.

Pérès K, Verret C, Alioum A and Barberger-Gateau P (2005) The disablement process: factors associated with progression of disability and recovery in French elderly people. Disability and Rehabilitation 27, 263-276.

Razani J, Casas R, Wong JT, Lu P, Alessi C and Josephson K (2007) Relationship between executive functioning and activities of daily living in patients with relatively mild dementia. Applied Neuropsychology 14, 208-214.

Rebok GW, Ball K, Guey LT, Jones RN, Kim HY, King JW, Marsiske M, Morris JN, Tennstedt SL, Unverzagt FW and Willis SL (2014) Ten-year effects of the Advanced Cognitive Training for Independent and Vital Elderly cognitive training trial on cognition and everyday functioning in older adults. Journal of the American Geriatrics Society 62, 16-24.

Richmond LL, Morrison AB, Chein JM and Olson IR (2011) Working memory training and transfer in older adults. Psychology and Aging 26, 813-822. 
Robertson S, Cooper C, Hoe J, Hamilton O, Stringer A and Livingston G (2017) Proxy rated quality of life of care home residents with dementia: a systematic review. International Psychogeriatrics 29, $569-581$.

Rozo V, Rodríguez O, Montenegro Z and Dorado C (2016) Efecto de la implementación de un programa de estimulación cognitiva en una población de adultos mayores institucionalizados en la ciudad de Bogotá. Revista Chilena de Neuropsicología 11, 12-18.

Sanjuán M, Calero MD, Abarca S and Navarro E (2018) Evaluation of the effects a caregiver training programme has on the cognitive and functional maintenance of the elderly. Estudios de Psicología 39, 437-464.

Simon SS, Castellani M, Belleville S, Dwolatzky T, Hampstead BM and Bahar-Fuchs A (2020) The design, evaluation, and reporting on non-pharmacological, cognition-oriented treatments for older adults: results of a survey of experts. Alzheimer's \& Dementia: Translational Research \& Clinical Interventions 6, e12024.

Smart CM, Karr JE, Areshenkoff CN, Rabin LA, Hudon C, Gates N and Hampel H (2017) Non-pharmacologic interventions for older adults with subjective cognitive decline: systematic review, meta-analysis, and preliminary recommendations. Neuropsychology Review 27, 245-257.

Spector A, Revolta C and Orrell M (2016) The impact of staff training on staff outcomes in dementia care: a systematic review. International Journal of Geriatric Psychiatry 31, 1172-1187.

Tardif S and Simard M (2011) Cognitive stimulation programs in healthy elderly: a review. International Journal of Alzheimer's Disease 2011, 1-13.

Teri L, Huda P, Gibbons L, Young H and Van Leynseele J (2005) STAR: a dementia-specific training program for staff in assisted living residences. The Gerontologist 45, 686-693.

Tzuriel D (2013) Mediated learning experience and cognitive modifiability. Journal of Cognitive Education and Psychology 12, 59-80.

United Nations (2017) World Population Prospects: The 2017 Revision, Key Findings and Advance Tables. New York, NY: United Nations.

Von Bastian CC, Langer N, Jäncke L and Oberauer K (2013) Effects of WM training in young and old adults. Memory and Cognition 41, 611-624.

Williams K, Herman R and Smith EK (2014) Cognitive interventions for older adults: does approach matter? Geriatric Nursing 35, 194-198.

Willis SL, Tennstedt SL, Marsiske M, Ball K, Elias J, Koepke KM, Morris JN, Rebok GW, Unverzagt FW, Stoddard AM and Wright E (2006) Long-term effects of cognitive training on everyday functional outcomes in older adults. Journal of the American Medical Association 296, 2805-2814.

Cite this article: Navarro E, Sanjuán M, Calero MD (2023). Increasing autonomy through improved care: effects of a professional care-giver training programme on the functional status of older adults. Ageing \& Society 43, 324-341. https://doi.org/10.1017/S0144686X21000519 